\title{
DIREITO AO RECURSO ENQUANTO GARANTIA DE DEFESA NO PROCESSO CRIMINAL
} RIGHT TO APPEAL AS A WARRANTY OF DEFENSE IN CRIMINAL PROCEEDINGS

\author{
Maria de Fátima Mata-Mouros de Aragão Soares Homem ${ }^{1}$ \\ Tribunal Constitucional - Portugal
}

\begin{abstract}
Resumo
O objeto da investigação é o direito de recorrer, no processo penal, quando houver uma absolvição no primeiro grau de jurisdição e uma condenação no segundo grau. Nesta hipótese, a previsão legal sobre a proibição de apelação da decisão de segundo grau é inconstitucional, porque a norma deve ser analisada à luz do direito constitucional de defesa.

Palavras-Chaves

Processo Penal. Irrecorribilidade. Condenação. Inconstitucionalidade.

\section{Abstract}

The object of the investigation is the right to appeal, in the Criminal Procedure, when there is an acquittal in the first degree of jurisdiction and a conviction in the second degree. In this hypothesis, the legal prediction about the probibition of appeal of the second degree's decision is unconstitutional, because the norm must be analyzed in the light of the constitutional right of defense.
\end{abstract}

Keywords

Criminal proceedings. Irrecorribility. Conviction. Unconstitutionality.

\section{INTRODUÇÃO}

No Acórdão n. ${ }^{\text {429/2016, de }} 13$ de julho de 2016, o Tribunal Constitucional de Portugal $^{2}$ julgou inconstitucional a irrecorribilidade para

\footnotetext{
${ }^{1}$ Juíza do Tribunal Constitucional - Portugal. Doutora em Direito pela Universidade Católica Portuguesa.

2 Em 13 de julho de 2016, o Tribunal Constitucional de Portugal decidiu, em Plenário, por maioria, julgar inconstitucional a norma que estabelece a irrecorribilidade do acórdão da Relação que, inovatoriamente face à absolvição ocorrida em 1. ${ }^{a}$ instância, condena os arguidos em pena de prisão efetiva não superior a cinco anos, constante do artigo $400 .^{\circ}$, n. $^{\circ}$
} 
o Supremo Tribunal de Justiça do acórdão proferido pelo Tribunal da Relação que, inovatoriamente face à absolvição ocorrida em 1. ${ }^{a}$ instância, condena os arguidos em pena de prisão efectiva não superior a cinco anos, por violação do direito ao recurso.

Este acórdão foi proferido no âmbito do Processo n. ${ }^{\circ}$ 1002/14, vindo a confirmar a tese da inconstitucionalidade afirmada no Acórdão do Tribunal Constitucional n. ${ }^{\circ}$ Acórdão n. ${ }^{\circ}$ 412/2015, de 29 de setembro de 2015, anteriormente proferido no mesmo processo. Estes arestos representaram uma evolução significativa na jurisprudência do Tribunal Constitucional relativa ao entendimento do direito ao recurso em processo penal.

\section{ENQUADRAMENTO INFRA-CONSTITUCIONAL DA QUESTÃO}

A questão de constitucionalidade colocada ao Tribunal Constitucional neste processo está relacionada com o regime de recursos em processo penal e a limitação do acesso aos tribunais superiores.

O enquadramento normativo do regime de recursos em processo penal conheceu uma evolução significativa desde a aprovação do Código de Processo Penal atual em 1987.

No Código de Processo Penal de 1987 só era admitido um grau de recurso, estabelecendo-se uma divisão "horizontal" de competências entre as Relações e o Supremo Tribunal de Justiça: do tribunal singular recorriase para as primeiras; do tribunal coletivo e do tribunal de júri recorria-se

1, alínea e), do Código de Processo Penal, na redação da Lei n. 20/2013, de 21 de fevereiro, por violação do direito ao recurso enquanto garantia de defesa em processo criminal, consagrado no artigo $32 .^{\circ}$, n. $^{\circ} 1$ da Constituição. O texto integral do acórdão, com o n. ${ }^{\circ}$ 429/2016, está disponível em http://www.tribunalconstitucional.pt/tc/acordaos/20160429.html. O presente texto visa apresentar aquele acórdão, pela inovação que representou na jurisprudência constitucional portuguesa. 
para o Supremo (artigos 427. e 432..$^{\circ}$ ). Mais se consagrava a configuração do recurso restrito à matéria de direito (recurso alargado). No recurso de facto, apenas previsto para as decisões do juiz singular, consagrava-se a possibilidade da renovação de prova na 2. ${ }^{\text {a }}$ instância bem como a possibilidade de reenvio para novo julgamento.

A renovação da prova apenas era consentida nas Relações, quando se verificasse insuficiência para a decisão da matéria de facto provada, contradição insanável da fundamentação ou erro notório na apreciação da prova e houvesse razões para crer que a renovação da prova pudesse evitar o reenvio (artigo 430. ${ }^{\circ}$, n. ${ }^{\circ} 1$ ), sendo o próprio tribunal ad quem que fixava, sem possibilidade de recurso, os termos e a extensão com que a prova produzida em primeira instância podia ser renovada (artigo 430. ${ }^{\circ},{ }^{\circ}{ }^{\circ}$ ).

Em consequência deste regime, fixada a matéria de facto em $1 .^{a}$ instância, apenas deficiências muito graves e improváveis verificadas na interpretação jurídica poderiam transmutar uma absolvição numa condenação (e muitas vezes apenas por via do reenvio), o que justificava a reduzida expressão que tinha o recurso em matéria de facto e tornava improvável uma inversão do sentido da decisão pelas Relações.

A Lei n. ${ }^{\circ}$ 59/98, de 25 de agosto, viria alterar este regime. Visando possibilitar o recurso em matéria de facto das decisões do tribunal coletivo, introduziu o duplo grau de recurso, passando assim a admitir-se um primeiro recurso para a Relação das decisões do tribunal coletivo (incluindo a matéria de facto) e um segundo recurso da decisão de $2 .^{a}$ instância para o Supremo Tribunal de Justiça (artigos 400. ${ }^{\circ}$, n. $^{\circ} 1$, alínea f), 427. ${ }^{\circ}, 428 .^{\circ}$, n. $^{\circ} 1$ e 432. ${ }^{\circ}$, alínea b) do CPP). A admissibilidade do duplo grau de recurso foi, no entanto, mitigada pela introdução de fatores de limitação do acesso ao Supremo Tribunal de Justiça baseados na gravidade da pena e na regra da "dupla conforme".

É neste contexto de contenção dos efeitos ao duplo grau de recurso, tendo em vista prevenir uma excessiva elevação de pendências no Supremo, que surge a alínea e) no elenco estabelecido no artigo $400 .^{\circ}$, n. $^{\circ} 1$ do CPP, excecionando da regra geral de recorribilidade (artigo 399..$^{\circ}$ ) os "acórdãos proferidos, em recurso, pelas relações, em processo crime a que seja aplicável pena de multa ou pena de prisão não superior a cinco anos, mesmo em caso de concurso de infrações, ou em que o Ministério Público tenha usado da faculdade prevista no artigo 16. ${ }^{\circ}$,.$^{\circ} 3$ ». As 
restrições previstas à recorribilidade em segundo grau conduziram a que, apesar do aumento da possibilidade de recurso em matéria de facto, ainda pudessem considerar-se residuais as hipóteses de conversão de uma absolvição em condenação por decisão irrecorrível da Relação.

Surge então a primeira apreciação pelo Tribunal Constitucional da conformidade constitucional da irrecorribilidade de acórdão condenatório da Relação proferido em sede de recurso interposto de decisão absolutória de primeira instância. Ao julgar a norma do artigo $400 .^{\circ}$, n. $^{\circ} 1$, alínea $e$ ), na redação dada pela Lei n. ${ }^{\circ}$ 59/98, o Tribunal Constitucional, no Acórdão n. ${ }^{\circ}$ 49/2003, não encontrou qualquer violação do artigo 32. ${ }^{\circ}$, n. ${ }^{\circ} 1$ da Constituição.

A revisão do CPP de 2007 (Lei n. ${ }^{\circ}$ 48/2007, de 29 de agosto) introduziria, todavia, uma nova disciplina na arquitetura do julgamento de recurso com o propósito de «restringir o recurso de segundo grau perante o Supremo Tribunal de Justiça aos casos de maior merecimento penali), (Exposição de Motivos da Proposta de Lei n. ${ }^{\circ}$ 109/X, que deu origem à Lei n. ${ }^{\circ}$ 48/2007), substituindo - para o que aqui nos interessa - o critério para aferir a irrecorribilidade da decisão da Relação proferida em recurso baseado na "pena abstratamente aplicável" pelo critério da "pena concretamente aplicada", tornando irrecorríveis apenas as condenações em pena não privativa da liberdade (artigo $400 .^{\circ}$, n. $^{\circ} 1$, alínea e)).

Por fim, com a revisão empreendida pela Lei n. ${ }^{\circ}$ 20/2013, foi introduzida a norma objecto de fiscalização pelo Tribunal Constitucional no acórdão que constitui o objecto da presente apresentação. Esta revisão introduziu alterações profundas na disciplina da admissão de recurso em segundo grau para o Supremo Tribunal de Justiça. Prosseguindo o desiderato da revisão de 2007, de restringir o acesso ao Supremo aos casos de "maior merecimento penal", o legislador modificou a alínea e) do n. 1 do artigo 400. ${ }^{\circ}$, aditando expressamente à lista de decisões irrecorríveis, os acórdãos proferidos em recurso pelas Relações que apliquem pena de prisão não superior a cinco anos, anunciando o propósito de resolver, em simultâneo, duas "deficiências" no sistema introduzido pela Lei n. 48/2007, que tinham sido diagnosticadas pela jurisprudência: por um lado, a crescente massificação do acesso à jurisdição do Supremo e, por outro, a 
assimetria do regime em desfavor da defesa, na configuração do duplo grau de recurso em processo penal.

\section{A QUESTÃO DE INCONSTITUCIONALIDADE}

A questão de constitucionalidade que se colocou por diversas vezes ao longo da evolução legislativa verificada consistia em saber se viola a garantia constitucional do direito ao recurso e garantias do direito de defesa (artigo 32. ${ }^{\circ}$, n. 1 da Constituição) a norma segundo a qual não é admissível recurso para o Supremo Tribunal de Justiça de acórdão da Relação, proferido em recurso interposto de decisão absolutória da primeira instância, que condene o arguido em pena de prisão não superior a cinco anos (artigo $400 .^{\circ}$, n. ${ }^{\circ} 1$, alínea e), do CPP, na redação dada pela Lei n. ${ }^{\circ}$ 20/2013, de 21 de fevereiro).

\section{AS TESES EM CONFRONTO}

\section{(i) A tese original}

A questão em análise contava já com expressiva jurisprudência do Tribunal Constitucional que invariavelmente se pronunciara no sentido da não inconstitucionalidade de uma solução normativa em certa medida semelhante à que recentemente viria a ser objecto de análise (no acórdão que constitui o objecto deste relatório), embora num contexto normativo anterior à Lei n. ${ }^{\circ}$ 20/2013, de 21 de fevereiro.

No Acórdão n. ${ }^{\circ}$ 49/2003, o Tribunal Constitucional concluiu que não desrespeita o artigo $32 .^{\circ}$, n..$^{\circ} 1$, da Constituição, a norma da alínea e) do n. 1 do artigo $400 .^{\circ}$ do Código de Processo Penal (na redação da Lei n. ${ }^{\circ}$ 59/98, de 25 de agosto), «por o acórdão da Relação consubstanciar a garantia do duplo grau de jurisdição, tendo em conta que perante ela o arguido tem a possibilidade de expor a sua defesa».

Reconhecendo estar perante uma limitação do direito de recurso, o Tribunal Constitucional considerou, no entanto, naquele acórdão, que aquela restrição não era inconstitucional. A argumentação deste aresto passa pela aceitação de que, existindo duplo grau de jurisdição, não é desconforme à Constituição a não consagração do direito de recorrer da decisão da segunda instância, porquanto se verificam dois fundamentos que justificam aquela limitação: por um lado, a circunstância de os crimes em causa terem 
uma gravidade não acentuada e, por outro lado, a intenção de limitar em termos razoáveis o acesso ao Supremo Tribunal de Justiça, evitando a sua eventual paralisação.

Naquele acórdão, o Tribunal, recordando os fundamentos que se encontram na génese do direito ao recurso ( «a ideia de redução do risco de erro judiciário», proporcionada pelo «reexame do caso por um novo tribunal», designadamente «através de um novo olhar sobre o processo, olhar esse que, por se encontrar deferido a um «tribunal superior», tem ainda a «virtualidade de oferecer uma garantia de melhor qualidade potencial da decisão obtida nesta nova sede»; por um lado e, por outro, «a faculdade de expor perante um tribunal superior os motivos - de facto ou de direito que sustentam a posição jurídico-processual da defesa», permitindo-se que o arguido apresente «perante um tribunal superior, a sua visão sobre os factos ou sobre o direito aplicável, por forma a que a nova decisão possa ter em consideração a argumentação da defesa»), reconduziu aquele direito tendencialmente à garantia do «duplo grau de jurisdição», concluindo que, havendo fundamentos razoáveis, a garantia do direito ao recurso seria compatível com a limitação da possibilidade de um triplo grau de jurisdição, concretizada na abertura do acesso ao Supremo Tribunal de Justiça.

Este entendimento viria a ser replicado invariavelmente pelo Tribunal noutros acórdãos.

É também nesta orientação jurisprudencial que se insere o Acórdão n. ${ }^{\circ}$ 163/2015, que pronunciando-se sobre a conformidade constitucional da norma do artigo 400. ${ }^{\circ}$ n..$^{\circ} 1$, alínea e) do Código Penal, na versão introduzida pela última revisão do Código de Processo penal operada pela Lei 20/2013, replica o juízo de compatibilidade com o artigo $32 .^{\circ}$, n. ${ }^{\circ} 1$, da Constituição — o primeiro segmento da alínea e) do n. 1 do artigo $400 .^{\circ}$ do Código de Processo Penal, na redação conferida pela Lei n. ${ }^{\circ}$ 20/2013, na interpretação segundo a qual não é recorrível para o Supremo Tribunal de Justiça o acórdão do Tribunal da Relação que, revogando a absolvição decretada em primeira instância, condena o arguido em pena de prisão efetiva não superior a 5 anos.

Foi deste último julgamento que o Acórdão n. ${ }^{\text {o }}$ 429/2016 viria a afastar-se expressamente, ao considerar insuficientes os fundamentos invocados anteriormente na jurisprudência constitucional para justificar, 
perante a privação da liberdade, a compressão do direito ao recurso traduzida na eliminação da possibilidade de acesso ao Supremo Tribunal de Justiça nos casos em que a Relação, revogando a decisão absolutória proferida em primeira instância, condena o arguido em pena de prisão efetiva não superior a cinco anos.

\section{(ii) A tese oposta}

No caso que viria a dar origem ao Acórdão n. ${ }^{\circ}$ 412/2015, os recorrentes foram absolvidos, em primeira instância, dos crimes de que eram acusados.

Interposto recurso pelo assistente, por acórdão de 28 de Janeiro de 2013, o Tribunal da Relação de Lisboa, julgando parcialmente procedente o recurso, decidiu alterar a matéria de facto fixada em primeira instância e condenar os arguidos em penas de prisão efectiva.

Os arguidos interpuseram recurso desta decisão para o Supremo Tribunal de Justiça, que entendeu não ser o mesmo admissível. Foi desta decisão que foi interposto o recurso de constitucionalidade para o Tribunal Constitucional.

A questão de constitucionalidade que constituiu o objecto central do recurso foi a seguinte:

- A irrecorribilidade para o Supremo Tribunal de Justiça do acórdão proferido pelo Tribunal da Relação que, inovatoriamente face à absolvição ocorrida em 1. ${ }^{a}$ instância, condena os arguidos em pena de prisão efectiva não superior a cinco anos (resultante do artigo 400. ${ }^{\circ}$, n. ${ }^{\circ} 1$, alínea e), do Código do Processo Penal, na redacção dada pela Lei n. ${ }^{\circ}$ 20/2013, de 21 de Fevereiro), viola o direito ao recurso que integra as garantias do direito de defesa em processo penal, nos termos do artigo $32 .^{\circ}$, n. $^{\circ} 1$ da Constituição?

A resposta do Tribunal Constitucional português foi afirmativa.

Neste acórdão, o Tribunal Constitucional acentuou que, sendo razoável limitar o acesso ao Supremo Tribunal de Justiça em ordem a prevenir a sua eventual paralisação, tal não deve, todavia, ser alcançado à custa das garantias de defesa do arguido. $\mathrm{O}$ artigo 32. ${ }^{\circ}$, n. ${ }^{\circ} 1$, da Constituição assegura ao arguido todas as garantias de defesa, incluindo o direito de recurso, designadamente da decisão condenatória. A consagração deste direito de recurso obriga à recorribilidade pelo arguido de acórdão 
condenatório em pena privativa da liberdade proferido em segunda instância, em revogação de absolvição da primeira instância. $\mathrm{O}$ direito do arguido ao recurso da sua condenação não se basta com o exercício do contraditório no recurso interposto pelo assistente da sua absolvição - o direito ao recurso é o efectivo poder de suscitar uma reapreciação da decisão jurisdicional condenatória. Para tal, o arguido tem de conhecer os fundamentos dessa decisão, o que não é possível garantir com a norma em apreciação, desde logo porque a decisão condenatória pode integrar matéria não abrangida pela decisão de primeira instância, designadamente no que respeita ao acervo factual relevante para a escolha e determinação da medida da pena aplicada. Mesmo que esse processo decisório se sustente apenas nos factos apurados em primeira instância, ele implicará necessariamente uma valoração assente num critério de doseamento da medida da pena que ao arguido só é revelado com a sua condenação. Só após a decisão ser proferida pode existir pleno exercício do direito de recurso quanto a essa decisão.

Sendo assim, imperioso foi concluir que a irrecorribilidade da decisão condenatória em pena de prisão proferida em segunda instância e em revogação da absolvição proferida em primeira instância, viola as garantias de defesa do arguido, em especial o seu direito ao recurso consagrado no artigo 32..$^{\circ} n^{\circ} 1$, da Constituição. De facto, a norma constante do artigo $400 .^{\circ}$, n. $^{\circ} 1$, alínea e) do CPP, ao resolver contra o arguido a situação de contradição entre a decisão de primeira e segunda instâncias, recusando-lhe a possibilidade de reação a uma condenação em pena de prisão efectiva viola concretamente os seus direitos de defesa.

Em face do exposto, concluiu a $1^{\text {a }}$ Secção do Tribunal Constitucional que a norma sindicada viola as garantias de defesa em processo penal, em especial o direito ao recurso, decorrentes do artigo 32. ${ }^{\circ}$, n. ${ }^{\circ} 1$, da Constituição, ao prever a inadmissibilidade de recurso do acórdão da Relação, que invertendo o julgamento absolutório proferido pelo tribunal de julgamento em primeira instância, afirma um juízo de culpabilidade do arguido e condena-o em pena de prisão efetiva até cinco anos de prisão.

\section{O ACÓRDÃO N. ${ }^{\circ} 429 / 2016$}


Diante da oposição de julgados verificada entre o Acórdão n. ${ }^{\circ}$ 163/2015, da 3. ' Secção, e o Acórdão n. ${ }^{\circ} 412 / 2015$, foi interposto recurso para o Plenário do Tribunal.

Quando uma tal situação ocorre, a Lei do Tribunal Constitucional (LTC) determina a necessidade de o Ministério Público recorrer para o plenário, como ocorreu (artigo 79. ${ }^{\circ}-\mathrm{D}$, n. $^{\circ} 1$, da LTC).

É neste contexto que surgiu o Acórdão n. ${ }^{\circ} 429 / 2016$, proferido pelo Plenário do Tribunal Constitucional após as $1 .^{a}$ e 3. Secções do Tribunal Constitucional terem julgado em sentido divergente a mesma questão de constitucionalidade.

A questão a dirimir consistia em de saber se é, ou não, conforme à Constituição a seguinte norma:

A irrecorribilidade do acórdão proferido pelo Tribunal da Relação que, inovatoriamente face à absolvição ocorrida em 1. 'instância, condena os arguidos em pena de prisão efectiva não superior a cinco anos, resultante do artigo $400 .^{\circ},{ }^{\circ}{ }^{\circ} 1$, alinea e), do CPP, na redacção introduąida pela Lei n. ${ }^{\circ}$ 20/2013, de 21 de Fevereiro.

Os elementos caracterizadores da norma apreciada são o facto de ter existido uma decisão absolutória da primeira instância que é revertida pela decisão do Tribunal da Relação e essa reversão resultar na condenação em pena de prisão efectiva.

\section{A DECISÃO}

No Acórdão do Plenário n. ${ }^{\circ}$ 429/2016 o Tribunal Constitucional português decidiu, por maioria:

Julgar inconstitucional a norma que estabelece a irrecorribilidade do acórdão da Relação que, inovatoriamente face à absolvição ocorrida em 1. ${ }^{a}$ instância, condena os arguidos em pena de prisão efetiva não superior a cinco anos, constante do artigo $400 .^{\circ}, \mathrm{n}^{\circ}$ 1, alínea e), do Código de Processo Penal, na redação da Lei n. $20 / 2013$, de 21 de fevereiro, por violação do direito ao recurso enquanto garantia de defesa em processo criminal, consagrado no artigo 32. ${ }^{\circ}$, n. $^{\circ} 1$ da Constituição 
O direito ao recurso constitui uma das mais importantes dimensões das garantias de defesa do arguido em processo penal;

A identificação expressa no artigo $32 .^{\circ}$, n. ${ }^{\circ} 1$, da Constituição do direito ao recurso como garantia de defesa, resultante da revisão constitucional de 1997 (não tendo implicado novidade relativamente ao entendimento que vinha já sendo feito pelo Tribunal Constitucional da sua redação anterior) representa o reconhecimento explícito da autonomia conferida a uma tal garantia no contexto geral das garantias de defesa, isto é, um valor de garantia não amortizável pelo reconhecimento de outras garantias processuais, designadamente para defesa do arguido.

Apesar da sua interligação, deve distinguir-se a garantia do "direito ao recurso" da garantia da existência de um "duplo grau de jurisdição", sob pena de diluição do valor próprio e autónomo que a Constituição reconhece, no artigo $32 .^{\circ}$, n. $^{\circ} 1$, ao direito ao recurso no contexto das garantias de defesa. Enquanto a Constituição consagra expressamente o direito de recurso em processo penal, nada refere sobre os graus de jurisdição exigíveis para concretizar o direito ao recurso. A garantia de defesa constitucionalmente prevista é autónoma em relação aos graus de recurso.

A liberdade conformadora do legislador na definição da recorribilidade das decisões judiciais e do regime de recursos em processo penal não pode deixar de encontrar como limite aquele direito constitucionalmente consagrado.

Embora não mereça contestação - pelo menos ao nível das exigências de um processo justo - que o "duplo grau de jurisdição" é pressuposto do exercício do direito ao recurso, reconhecendo a jurisprudência do Tribunal Constitucional a possibilidade de o direito ao recurso se consumar também através da existência desse duplo grau de jurisdição, tal não significa que baste o duplo grau de jurisdição para se considerar sempre assegurado o direito ao recurso.

Para que a garantia de duplo grau de jurisdição concretize o direito de recurso é indispensável que a apreciação do caso por dois tribunais de grau distinto se apresente como tutela suficiente das garantias de defesa constitucionalmente consagradas. 
O Tribunal Constitucional tem incluído no «conteúdo essencial das garantias de defesa» o direito de recorrer de decisões condenatórias e de atos judiciais que, durante o processo, tenham como efeito a privação ou a restrição da liberdade ou de outros direitos fundamentais do arguido.

A jurisprudência do Tribunal Europeu dos Direitos do Homem transmite a percepção clara de que a reversão, em via de recurso, de uma absolvição em condenação convoca um elevado nível de exigências garantísticas da posição processual do arguido.

No caso da norma em apreciação no presente recurso - em que existe uma absolvição da primeira instância revogada por decisão condenatória em pena de prisão da segunda instância - não é assegurada no julgamento do recurso uma reapreciação das consequências jurídicas do crime; trata-se, pelo contrário, de uma decisão inovadora com consequências fundamentais na posição jurídica do arguido, designadamente na sua liberdade, relativamente à qual é negado o acesso a uma reapreciação por um tribunal superior.

Uma situação em que a uma absolvição de primeira instância sucede a condenação em pena de prisão, no tribunal de recurso, implica necessariamente o surgimento de toda uma parte da decisão que se apresenta como integralmente nova.

A irrecorribilidade da decisão condenatória neste contexto significa prescindir da reapreciação por uma segunda instância da decisão que define a pena de prisão efetiva, apresentando-se a decisão do juiz quanto à escolha e determinação da medida da pena de prisão como livre de qualquer controlo, o que é inaceitável.

No caso da norma sob escrutínio, o arguido só toma conhecimento do fundamento, tipo e quantum da pena em que vai condenado através do acórdão do Tribunal da Relação, que o condena, apenas nesse momento estando logicamente em condições para recorrer dessa decisão, já que antes ela nem sequer existe; neste caso, o direito do arguido ao recurso da sua condenação não se pode bastar com o exercício do contraditório no recurso interposto pelo Ministério Público da sua absolvição.

Embora sejam diversificadas as soluções configuráveis no sistema de recursos em processo penal com vista à harmonização do interesse na otimização dos recursos e o célere funcionamento da justiça com os direitos 
de defesa do arguido, impedir o arguido de rebater, com argumentos próprios, os fundamentos e critérios de escolha e determinação da medida da privação da sua liberdade, que pode estender-se até cinco anos, consubstancia uma ablação total daquele direito que é inadmissível pois atinge as suas garantias essenciais de defesa.

Sendo em si mesmo razoável limitar o acesso ao Supremo Tribunal de Justiça de forma a prevenir a sua eventual paralisação, tal não deve ser alcançado à custa do sacrifício do conteúdo essencial das garantias de defesa do arguido.

A discricionariedade do legislador quanto à definição do rol das decisões recorríveis e ao regime do respetivo recurso conhece como limite o dever de não ablação do direito ao recurso nas situações referidas pela jurisprudência do Tribunal Constitucional; no presente caso, em que existe uma condenação e uma decisão de privação de liberdade, proferida pela segunda instância, após uma absolvição, pela primeira instância, estamos perante uma violação desse dever.

A norma objeto do processo, ao resolver contra o arguido a situação de contradição entre a decisão de primeira e segunda instâncias, recusandolhe a possibilidade de reação a uma condenação em pena de prisão efetiva, é inconstitucional por violar o artigo 32. ${ }^{\circ}$, n. ${ }^{\circ} 1$, da Constituição. 